\title{
Be going to and will: a pragmatic account ${ }^{1}$
}

\author{
LILIANE HAEGEMAN
}

\author{
Department of English, University of Geneva
}

(Received 8 October 1987 ; revised 26 January 1989)

\section{INTRODUCTION}

In the literature on English tense usage, expressions of futurity such as

(I) (a) I will/shall leave next week.

(b) I'm going to leave next week.

have already received a lot of attention, especially so in the pedagogical descriptive tradition of English linguistics (cf. Close, I977; Haegeman, I98 I, 1983; Leech, 1971; Quirk et al., 1985; Palmer, 1974, I979; Wekker, 1976, etc.). Although these accounts are attractive, they raise further questions because most of them do not propose to deal with the problem against a formal theoretical background. As a consequence, the rules formulated to describe the use of shall/will or be going to in (I) tend to be intuitive and often do not really allow any decisive choice to be made in many instances of usage. On the other hand, Reichenbach type analyses of tense interpretation are usually mainly concerned with the general problem of tense representation and treat both examples in ( $\mathrm{r}$ ) as illustrations of future tense without detailed discussion of the contrasts between them.

In this paper I shall try to throw some light on the selection of the future time expressions in (I). My paper reinterprets the descriptive accounts referred to above against the background of the theory of utterance interpretation known as Relevance Theory (Sperber \& Wilson, 1986). The descriptive studies amalgamate the different levels of utterance interpretation and fail to distinguish a sentence-based 'grammatical' level of interpretation ('semantics') from a discourse or context-based non-grammatical level ('pragmatics'). Based on Smith's (I98I) discussion of tense and time, I will try to argue that at the level of sentence meaning be going to and shall/will are equivalent, and that the difference between them is to be found in the constraints they impose on the processing in context of the utterance in which they occur. The two forms are thus interpreted as ways of

[1] This paper was first presented at the LAGB spring meeting in London in 1987 and subsequently at the IPRA conference in Antwerp in August 1987. I wish to thank the participants of these conferences and of my pragmatics seminar in Geneva in 1987-8 for their helpful comments. Thanks are due to the following: Neil Smith, Nigel Vincent and especially Sten Vikner and two anonymous referees of the Journal of Linguistics. Needless to say they cannot be held responsible for the way I have used their comments. 


\section{LILIANE HAEGEMAN}

grammatically encoding processing constraints on the utterance in which they appear. Section 2 provides a review of some of the pedagogical and descriptive literature on be going to, concentrating on Wekker (1976) and on Leech (I97I), ${ }^{2}$ which offer the most detailed accounts. These descriptive studies will be the starting point of the analysis. This section also briefly discusses a Reichenbach type analysis of tense interpretation and the problems that arise there. Section 3 is mainly descriptive. It focuses on two contextual properties of be going to: ellipsis and its rare occurrence in association with conditionals. Section 4 focuses on the parallelism between be going to and the present perfect. Section 5 proposes an alternative analysis for the selection of shall/will vs be going to modelled on Smith's (198I) analysis of the present perfect. Section 6 is more speculative and suggests ways of integrating the pragmatic account with the 'traditional' accounts of tense representation.

\section{BE GOING TO VS WILL ${ }^{3}$ IN THE LITERATURE}

\section{I. The descriptive tradition}

2.I.I. A semantic distinction. It has often been pointed out that the use of be going to/will in English offers major problems to foreign language learners (cf. Wekker, 1976: 123). An interesting aspect of this problem is that an inappropriate use of be going to/will cannot usually be said to lead to ungrammaticality, rather, as is suggested by most authors, it leads to a certain un-Englishness, and this is often seen as illustrating a lack of idiomaticity. To suggest that the appropriate use of will or be going to is largely a matter of idiomaticity seems to imply that it is an accidental property of English rather than being systematic. As we shall see below there is certainly a systematicity in the use of either construction in English. Moreover the use of the verb go in future tense constructions is not a property of English only but is widely found in other Germanic and Romance languages (see Fleischman, 1982, and Vet, 1984, for discussion of the Romance data). I shall not go into these other languages here but I would of course hope that the account proposed here may carry over to at least some of them.

The observation that an inappropriate use of be going to or will does not cause ungrammaticality or semantic anomaly is important, though, as it might suggest that we are not dealing with the violation of a formal grammatical principle of tense selection but rather with the infringement of some principle governing the appropriate use of a construction in a context,

[2] I have used the first edition of Leech's book for quotations. A second edition appeared in 1987.

[3] I am only going to be concerned with the so called 'pure future' or 'future tense' use of shall and will and will not go into the other meanings attributed to these modals. I also do not enter into the discussion as to whether the future tense is to be treated on a par with past and present tense (cf. Palmer, 1974, 1979; Haegeman, 1981, 1983; Wekker, 1976). From now on I will use the modal will to represent the future tense. 
i.e. a pragmatic principle. This point of view differs from the general assumptions made more or less explicitly in the standard literature on the issue. ${ }^{4}$ When discussing the contrast between will and be going to, most authors seem to argue that there is a clear semantic difference between the two. The quotations below are illustrative and other similar ones can be found in the literature.

Concerning be going to Leech (1971) writes:

If there is one general meaning that can be attached to this construction, it is FUTURE FULFILMENT OF THE PRESENT. In fact, however, it is useful to discriminate between two meanings, the FUTURE CULMINATION OF PRESENT INTENTION and the FUTURE CULMINATION OF PRESENT CAUSE. (54, italics mine, capitals his)

The future culmination of present intention and the future culmination of present cause are illustrated in ( $2 a)$ and $(2 b)$ respectively.

(2) (a) They're going to get married in a registry office.

(b) She's going to have another baby.

Given that Leech does not use any theoretical background, it is not obvious what he means by the term 'meaning'. It would be interesting to know whether Leech considers will and be going to to be truth conditionally distinct. Furthermore, if be going to has two 'meanings' then one might infer that it will on occasions be ambiguous between two interpretations, 'intention' and 'cause'. It seems to me, though, that it would be hard to treat the examples with be going to as 'ambiguous' in a truth conditional sense. Consider, for instance, the following example:

(3) They are going to get married.

If be going to is genuinely ambiguous, this sentence would have two interpretations, with different truth conditions:

(a) There are present indications that they are going to get married.

(b) They intend to get married.

However it would seem to me that a sentence like (4) is a contradiction:

(4) They are going to get married but they are not going to get married.

It does not seem that (4) can be interpreted as:

(c) 'They intend to get married, but there are no present indications that they are getting married'.

Only by adding further contextual information could the two interpretations be brought out. This would support the idea that be going to is

[4] It is possible that the approach adopted here may also be used to throw light on aspectual distinctions. This will have to be the object of further research (cf. Ehrlich, 1987; Hopper, 1979, 1982). 


\section{LILIANE HAEGEMAN}

vague between the various interpretations suggested and that the context determines more specific readings.

Note also that indeed (3) can simultaneously have both interpretations (a) and (b). If the sentence is genuinely ambiguous this would be rather unexpected. (I return to this point in 5.2.3.)

Wekker (1976) offers a very comprehensive survey of the literature on be going to and he too distinguishes it from will in terms of semantics:

the semantic condition governing the use of be going to is the fact that there must be indications in the present that something will happen ( 126 , italics mine)

Will and be going to are said to have different 'implications'. For be going to

its implication is loosely that there are indications in the present that something will happen (I24, italics mine)

It contrasts with will whose 'orientation is towards the future' (125). Again in Wekker's work terms such as 'semantic condition' or 'implication' are pre-theoretical. In these circumstances it is hard to decide what the term 'implication' in the citation above is supposed to refer to: logical entailment, presupposition or possibly generalized conventional or conversational implicature (cf. Grice, 1975). While mention is made of stylistic factors determining the choice of be going to vs will, it seems that the author considers the basic contrasts to be 'semantic', i.e. confined to the level of grammatical sentence-meaning.

Most other studies in the descriptive tradition implicitly argue for a semantic opposition between will and be going to, but in one earlier discussion of the English verb Palmer (1974: 163) argues that in many cases there is no such contrast:

In most cases there is no demonstrable difference between will/shall and BE GOING To though many scholars have looked without success for one. ${ }^{5}$

It will turn out that Palmer's informal account is the one that I shall be adopting later on. In subsequent work, however, Palmer adopts Wekker's (I976) analysis.

2.1.2. 'Present orientation' vs 'future orientation'. As the above citations have already indicated, it is generally agreed that be going to conveys 'present orientation'. In this section I shall briefly review the content that this concept is given. Wekker (1976: I24) provides a fairly detailed description of his view of 'present orientation':

it is clear that the notion of present indication, circumstances or conditions must be taken in a rather wide sense. It must, for example, include such

[5] As will be seen below, Palmer's (1974) analysis is thus close to my own. 
ideas as 'present cause' or 'present intention' '... which, in a very real sense, are felt by the speaker to be present circumstances associated with a future event or action.

The description of the notion 'present orientation' is not very precise. Note, for example, that Leech (1971: 56) also points out that the notion of 'present determination of the future' is not well-defined:

If one takes a fatalistic view of the future, of course, any coming event, however remote, may be thought to have its seeds in the present, and in any case, there is often in people's speech a sense of destiny vague enough to bring be going to almost as close to a neutral 'future tense' as will/shall.

This quotation is interesting because Leech seems to admit that the speaker's own background assumptions may determine the selection of one form or the other, which again hints at a pragmatic factor in the selection of the form.

In his discussion of shall/will Wekker (1976:39) writes:

will and shall may function as markers of the future tense ... the future may be used to express a wide variety of nuances of meaning ... the meaning of this tense may range from a plain or purely factual statement about the future... to a more tentative speculation or prognostication.

But notions such as 'prognostication' and 'speculation' also suggest a present basis for the future prediction and the suggestion of a link between present and future is reinforced in the following quotation (Wekker 1976: 67):

future reference is necessarily based on the speaker's knowledge, beliefs and assumptions

These quotations lead us to conclude that there is no clear line to be drawn between the meaning of will in contrast to that of be going to and that often it is the speaker's perception of the future event as being either firmly embedded in the present or more related to future events which is decisive.

One might try to sharpen the discussion of the so-called semantic contrast between be going to and will by using some formal contrast such as cooccurrence constraints with time adverbs. But compatibility with time adverbs is not unproblematic: both will and be going to cooccur with now which seems to be the prototype of a present time adverb.

(5) (a) Now I'm going to have to take this dress to the cleaners again.

(b) Now we'll have no money at the end of the month. (cf. the discussion in Haegeman, 1983: 155)

One problem with the examples in (5) is that the adverb now is not just temporal. Rather, it suggests that the event expressed in the main proposition is the consequence of a prior event. A more likely candidate to bring out 
contrasts is already. In Haegeman (I983a: 156$)$ it is shown that already cooccurs with be going to rather than will:

(6) (a) We are already going to have the kitchen redecorated, we cannot have the builders in too.

(b) ?We already will have the kitchen redecorated, ...

Like now, already is more than a simple time adverb which locates the event or state in the sentence at some point in time. Already relates this event to the other events in the immediate context. Consider for instance:

(7) (a) The secretary had left when John arrived.

(b) The secretary had already left when John arrived.

In (7a) the secretary's departure may coincide with or precede John's arrival but in ( $7 \mathrm{~b}$ ) already seems to force the latter reading (cf. Hornstein's discussion 1977: 547-8). Given that already is used as a means of organizing a proposition with respect to its context, it can be argued that it has a discourse function: it imposes 'pragmatic' constraints on processing. It is important that precisely such a 'pragmatic' adverb distinguishes between be going to and will.

\subsection{The Reichenbach approach to tense interpretation}

It has become customary to view tense interpretation in terms of semantic analysis and one type of analysis that has gained some popularity is that proposed by Reichenbach. I shall not go into a full discussion of the merits of the approach here (see for example Vikner, 1985, and Enç, 1987, for recent criticisms of this approach). I shall merely examine here how the contrast between will and be going to could be stated in Reichenbachian terms. As is well known, Reichenbach uses three components to determine the temporal location of a proposition:

(8) (i) S: the moment of speech

(ii) $\mathrm{E}$ : the time of the event

(iii) $\mathbf{R}$ : the reference point

He proposes the following representations for the simple past and the present perfect in English:

(9) (a) Simple past John left. E, R-S

(b) Present perfect John has left. E-R,S

He further proposes that the will future is ambivalent between the following interpretations:

(I0) (a) $S, R-E$

(b) $\mathrm{S}-\mathrm{R}, \mathrm{E}$ 
He arrives at this conclusion on the basis of the observation that both a present time adverb and a future time adverb can be associated with the construction:

(I I) (a) Now I shall go.

(b) I shall go tomorrow.

In this account time adverbs are said to identify uniquely the position of $R$. But, as Hornstein (1977) shows, this restriction cannot be maintained. A present time adverb and a future time adverb may be present simultaneously in a sentence with will:

(I I) (c) Now we'll have no money at the end of the month.

As we have already seen, be going to allows for the same adverbial specifications:

(I2) (a) Now I'm going to go.

(b) I'm going to go tomorrow.

(c) Now I'm going to have no money at the end of the month.

Reichenbach's own account does not deal with this use of be going to. He only discusses the construction in the light of the 'posterior future' (see discussion in Section 6.3). If we adopt his analysis of will and use cooccurrence with time adverbials as the diagnostic for the tense representations, then ( 11 ) and (I2) lead us to conclude that will and be going to will have the same tense representation, namely that in (I0). If these representations are to be related to truth conditions (see discussion in Section 5.1), then we should conclude that will and be going to are truth conditionally equivalent. This means that there would be an asymmetry with the past time expressions as presented in (9), which should be truth conditionally distinct since they have distinct tense representations.

Alternatively we could adapt Reichenbach's proposal for French future time expressions to the English constructions.

(13) (a) Futur proche: Je vais voir Jean S,R - E

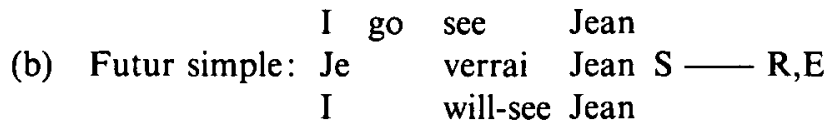

(see discussion in Fleischman (1982) for similarities between aller and be going to). The representation in ( 13 a) would be used for be going to and that in $(13 b)$ for will.

(14) (a) I'm going to see John. S,R - E

(b) I shall see John. $\quad \mathrm{S}-\mathrm{R}, \mathrm{E}$

There would then be a parallelism between the two expressions for past time in (9) and those for futurity in (14). We return to this parallelism below 
(Section 4). The fact that be going to in (14a) and the present perfect are morphologically present tense could be related to the positioning of the reference point. On this assumption, the contrast between 'present orientation' for be going to and 'future orientation' for will can also be seen as a function of the position of the reference point $\mathrm{R}$. For will it is associated with the time of the event $\mathrm{E}$, i.e. it is in the future; for be going to $\mathrm{R}$ is associated with the moment of speech, the present. However, the tense representations in (14) could no longer be related to cooccurrences with adverbials such as now, as suggested by Reichenbach. As we have seen, the adverb already would be more appropriate. I return to this issue in Section 6.

In the following sections I shall first return to the data and consider in more detail the contexts in which the expressions are used.

\section{CONTEXTUAL CHARACTERISTICS OF BE GOING TO}

Apart from the cooccurrence with already mentioned above we can identify other properties of the constructions analysed which hint at pragmatic distinctions in that they relate to contextualization rather than to sentence bound phenomena.

\section{I. Ellipsis}

One interesting aspect of the use of be going to as opposed to will is pointed out by Binnick (1972) and discussed in Wekker (1976: 127). Binnick observes that a sentence containing will is often felt to be elliptical in the sense that it is incomplete as it stands. Such an 'elliptical' sentence may be completed by another clause, or by material presented in an earlier sentence or phrase. On the other hand, he claims, a sentence with be going to is never felt to be elliptical; it is complete as it stands. Thus ( $15 \mathrm{a}$ ) is felt to be elliptical, ( $15 \mathrm{~b}$ ) is not:

(I5) (a) The rock will fall.

(b) The rock is going to fall. ${ }^{6}$

One question is what it means for (15a) to be 'elliptical'. Presumably the implication is not that obligatory or optional sentence internal material is

[6] As pointed out by one anonymous referee, the intonation plays an important part in these examples. I shall not go into the role of intonation here. It would appear that intonation is a guide offered by the speaker for the interpretation of the utterance. In an example like (i) below, rising intonation, for instance, will indicate that, contrary to the overt form, the sentence is to be taken as a question:

(i) You are not going. 
missing (cf. Wekker's discussion) or has been deleted. What seems to be at issue is that while a sentence with be going to can appear fairly naturally without there being any linguistic context, a will sentence like ( 15 a) requires such a context. Wekker $(1976: 128)$ explains the phenomenon as follows:

ellipsis is a secondary phenomenon which can be explained in terms of the notion of logical dependence upon other events implied or overtly expressed in the context. In other words, inherent in the meaning of be going $t o$ is the implication that there are present indications or circumstances which suggest that something will happen. This is the reason why sentences with be going to are never felt to be elliptical as they stand. On the other hand, sentences containing will/shall are often elliptical, precisely because it is not inherent in their meaning that all conditions for the future event have necessarily been met.

This explanation is not entirely satisfactory. It is not stated when exactly sentences with will/shall will be felt to be elliptical (cf. Wekker's use of 'often'). Also, it is not obvious why precisely the will sentence, which was said to lack inherent implications as to present conditioning of the future, should be the one that is incomplete without explicitation of the conditions of the future event. Given that the notion 'inherent implication' is rather vague, it is hard to pin down exactly Wekker's analysis.

\subsection{Conditionals}

It has been pointed out (cf. Leech, 1971:56) that conditional sub-clauses are relatively rare with be going to. Leech contrasts the following (his judgments are given):

(16) (a) If you accept that job, you'll never regret it.

(b) *If you accept that job, you're never going to regret it.

Leech points out that the incompatibility of be going to with conditionals is not absolute:

be going to is suitable, however, if present circumstances are mentioned in the if-clause; i.e. if the condition is a present one rather than a future one:

(I6) (c) We're going to find ourselves in difficulty if we carry on like this. (Leech 1971: 56)

But in the right context, even (I6b) would not be ungrammatical. For instance, to someone who has just announced that he is accepting that job, ( $16 \mathrm{~b}$ ) would be an appropriate reply. ( $16 \mathrm{~b}$ ) would be inappropriate, it seems to me, though not ungrammatical, if both the event in the conditional subclause and that in the main clause are firmly to be placed in the future. 


\section{Future time and PAST TIME: A COMPARISON}

An important feature of the use of be going to was pointed out in earlier work by Joos (I964: I 4I ftn):

the meaning of BE GOING TO...turns out to be exact reversal, in every detail $\ldots$, of the meaning of the perfect phrase.

According to Joos (1964: 140):

the perfect phase means that the event is not mentioned for its own sake but for the sake of its consequences.

We conclude from this that be going to is used to refer to a future event that is not mentioned for its own sake but for the sake of its causes, an interpretation which is in line with those discussed above. The parallelism with the present perfect is also pointed out elsewhere. Wekker (1976: 125) discusses the following example:

(I 7) (a) Finally, tonight, on to the weather forecast for the South. The night is going to be rather cloudy, but most places will remain dry. The temperature will fall around 40 near the coast,... and the winds, they'll be south-east... (from Nationwide, BBC 20.2.75)

\section{Wekker writes:}

there is obviously very little difference in meaning between be going to and will in this spoken weather forecast. But the interesting point here is that this forecast like several others... begins with be going to, and then continues with will. This, I claim, is not merely a matter of style... but also something which has to do with the implications inherent in be going to and the will/shall construction. The explanation for this use of be going to is that the television weather man begins his forecast, as normally in conversation, from present indications or circumstances (such as the black clouds gathering, or after reading the newspaper forecast), and then switches his attention to the future, using will. A similar shift of perspective occurs elsewhere in the grammar: it often happens that a story or a song begins with the present perfect and then switches to the past tense. (I976: 125)

(I 7 b) illustrates a shift from present perfect to past tense parallel to the shift from be going to to will illustrated in (1 $7 \mathrm{a}$ ).

(I7) (b) A collection of 45 drawings ... has been sold by Sotheby's in New York for \$2 I,288,300... They were owned by Mr John Gaines, a race horse breeder whose fortune came from a dog food company. Mr Gaines decided to sell... (Guardian I9. I I.86, p. 2 coll 3-5) 
The symmetry between past tense/present perfect and will/be going to is also implied by Palmer (1979) who subsumes both present perfect and be going to under the label 'current' orientation. Other authors use the term 'current relevance' and have seen the same dimension as characterising the difference between will and be going to (see Fleischman, 1982). Wekker links the shift from be going to to will in (17a) to a change in perspective. Though he himself discusses this as a 'grammatical phenomenon', it seems that the shift of tenses has more to do with principles of discourse organization. In other words, it is not a sentence based phenomenon but one that deals with sentences in context, that is with pragmatics.

The parallelism between be going to and the present perfect also comes out in the fact that both are compatible with the time adverb already (see 2.I.2).

\section{Pragmatics and tense selection}

Smith (198I) presents a new analysis of tenses based on the theory of utterance interpretation known as Relevance Theory as developed by Sperber and Wilson (1986). I shall try to give a brief survey of the main points of the theory here. Obviously, its full scope cannot be developed here and the interested reader is referred to the literature.

\section{I. Relevance theory}

5.I.I. The principle of relevance. Central to Sperber and Wilson's theory is the concept of relevance. The interpretation of an utterance is subject to the principle of relevance, according to which speakers will try to maximize relevance. A proposition is relevant if it creates some contextual effect. An utterance will have some contextual effect if its interpretation in a specific context will allow the hearer to draw conclusions which he could not have drawn either from the context on its own or from the utterance on its own. In other words, a proposition is relevant if it can be hooked up to a context, a set of propositions available either in the linguistic context or in the memory store of the hearer. Consider for example the exchange in (I8):

(I8) A: If Ann is here the party will be a success.

B: Ann is here.

From the proposition expressed by $A$ and that expressed by $B$ one is entitled to draw the inference, by Modus Ponens, that 'the party will be a success'. This conclusion cannot be arrived at on the basis solely of either the utterance B on its own or the context A on its own. The conclusion is only achieved by the interplay of the utterance $B$ and its context. We then can say that $B$ has a contextual effect in the context in (I8).

Relevance is not an absolute notion. The contextual effect of an utterance is obtained at some cost: the hearer must process the utterance against the 
context. If the processing cost increases, the relevance diminishes. Compare the exchange in (18) with that in (19):

(I9) A: If Ann is here the party will be a success.

B: Ann has come by car.

Even though (19 B) still allows us to draw the conclusion that 'the party will be a success', it is less relevant than (I8 B) because it involves more processing. Two steps would be needed to arrive at the conclusion: the hearer would first have to derive from ( $19 \mathrm{~B}$ ) that Ann is here and then he could derive that the party will be a success. A speaker who simply wanted to convey that Ann is here and therefore that the party will be a success would not have respected the principle of relevance: he could have saved the hearer some processing effort by simply saying (I 8B). The additional information in (19B) merely involves extra processing without any added contextual effect.?

5.1.2. Processing constraints. Blakemore (1985), using the Relevance framework, shows how certain linguistic elements such as the co-called pragmatic connectors (e.g. so, also, etc.) fail to contribute to the truth conditions of the proposition(s) with which they are associated. Rather, they function as guidelines for the processing of the utterance in a context. After all, for instance, indicates that the proposition it is associated with is to be taken as a premise which can be used to support a conclusion.

(20) A: John is going to the LAGB.

B: After all, he is a linguist.

After all in ( $20 \mathrm{~B})$ indicates that the proposition 'he is a linguist' can be used as a premise to derive the conclusion that 'John is going to the LAGB'. In order to derive the conclusion the hearer will have to access another proposition which he will retrieve from his background knowledge, namely that 'linguists go to the LAGB'. The reasoning would be as follows:

(2I) (i) All linguists go to the LAGB. (from encyclopaedic knowledge)

(ii) John is a linguist.

Hence:

(iii) John is going to the LAGB.

The addition of after all in $(20 \mathrm{~B})$ guides the hearer of the utterance with respect to its interpretation. It increases the relevance of the utterance not because it adds more contextual inferences, but because it reduces the processing effort needed to derive the inferences. Compare (20) with (22):

(22) A: John is going to the LAGB.

$\mathrm{B}$ : $\mathrm{He}$ is a linguist.

[7] Note though that this too is relative. If the hearer had available as background knowledge the assumption that whenever Ann comes by car she is in a foul mood, then ( $17 \mathrm{~B}$ ) would allow him to draw the inference that though Ann is here the party may not be a success. 
After all in (20B) does not contribute to the truth conditions of the sentence. It is not possible to imagine, for example, that $(20 \mathrm{~B})$ might be true in a certain context and (22 B) false. Although the hearer of (22 B) might be led to draw the same conclusions as the hearer of (2OB) (see (2I)), alternative interpretations are possible. The hearer of $(22 \mathrm{~B})$ might for example consider this utterance itself as a conclusion drawn from $(22 \mathrm{~A})$, on the basis of the following reasoning:

(23) (i) All linguists go to the LAGB.

(ii) John is going to the LAGB.

\section{Hence:}

(iii) John is a linguist.

The speaker of $(20 \mathrm{~B})$ saves the hearer processing efforts by enabling him to choose immediately between the two interpretations of the proposition 'John is a linguist'. After all signals unequivocally that the utterance is to be taken as a premise. If instead the speaker had wished to make it clear that the utterance was to be taken as a conclusion, he could have introduced it with so:

(24) A: John is going to the LAGB.

B: So, he is a linguist.

\subsection{Relevance and tense selection}

5.2.1. Simple past and present perfect. Using the Relevance framework, Smith (198I) applies the idea that linguistic elements may encode processing instructions to the English tense system. Discussing the following examples:

(25) (a) John has scored a goal. (his (38))

(b) John scored a goal. (his (39))

he says

Despite claims to the contrary ... there is no good evidence that the past and the perfect are ever truth-conditionally distinct... they can never be consistently asserted and denied at the same time (198 I : 259)

and concludes:

the implication of this truth-conditional equivalence is that the contrast between [25a] and [25b] is at least in part pragmatic ( $198 \mathrm{I}: 260)$

In Smith's view the present perfect contains 'a subjective element incorporating the event described into the time of speech':

it indicates that the propositions relevant to the interpretation of the sentence include some present tense ones (1981:260)

In other words, the present perfect encodes an instruction for the processing of the proposition expressed: an utterance containing a present perfect must 


\section{LILIANE HAEGEMAN}

be processed at least partly against a present tense background or it must not be processed exclusively against past tense propositions. The fact that the present perfect is morphologically a present tense can clearly be related to this. The morphological tense determines the contextualizaton of the utterance. $^{8}$

As Smith points out, his proposal is in line with the traditional descriptive treatments of the present perfect in terms of 'current relevance', but it refines these analyses in explicitily situating the notion in the pragmatic domain of utterance interpretation. Let me just illustrate Smith's proposal with an example drawn from his article (examples (43)-(47)), which is in turn taken from Sperber and Wilson (1981).

(26) (a) If the chairman resigns, Jackson will take over his duties.

(b) If Jackson takes over the chairman's duties, the company will go bankrupt.

(c) The chairman has resigned.

By two applications of Modus Ponens, the propositions in (26) allow the conclusions:

(27) Jackson will take over the chairman's duties.

(28) The company will go bankrupt.

Concerning these examples Smith says:

It is clear that if [26c] were replaced by [29]:

[29] The chairman resigned.

there would be no such contextual implications. Although truthconditionally equivalent to [26c], the utterance of [29] in the simple past does not license the appropriate interaction with [26a] whose protasis is present and is therefore irrelevant in this context (Smith, 1981: 26I).

Smith also tries to explain the formal constraints on the use of the present perfect. $^{9}$

Perfect have is tied to speech time and is accordingly inappropriate if it occurs with elements which designate any period necessarily exclusive of

[8] I shall maintain the assumption that truth conditions are determined at the level of semantics although this is not uncontroversial (see Kempson, 1988 a,b,c, for discussion and also Sections 5.1 and 5.2 below).

[9] Smith does not discuss the fact that in many other languages the present perfect is compatible with past time adverbs:

(i) French

Je l'ai vu hier.

I have seen him yesterday.

(ii) Dutch

Ik heb hem gisteren geizien.

I have seen him yesterday. 
the present, e.g. temporal adverbials such as yesterday, phrases containing ago, last, etc. Accordingly, if have occurs with adverbials of this sort the utterance will if possible be reinterpreted as a habitual encompassing the present: Thus [30]:

[30] ?John has gone to Morocco on the Ist of June

is acceptable only if the sentence is amplified with an overt frequentative, as in [31]:

[3I] John has gone to Morocco on the Ist of June every year since I93I.

or if the context makes a frequentative reading self-evident (Smith I98I : 262).

He does not extend his analysis to complex tenses such as the past perfect where in fact both have and a past tense are present (see discussion below 6.3).

5.2.2. Be going to and will as constraints on processing. I would like to propose that Smith's analysis of the present perfect can be applied to the expressions of future time discussed here. Be going to is like the present perfect in that it imposes a constraint on the processing of the proposition with which it is associated. It signals that this proposition is relevant in a context including at least some present tense propositions, or, in other words, it guarantees a contextual effect if the utterance is processed against a present context. Will, on the other hand, signals that the hearer should extend the immediately accessible (present) context for the processing of the proposition and should process the utterance against future propositions. The selection of either be going to or will is thus relevant in that it indicates not simply that an event will take place in the future but also that the proposition expressing that event should be processed against a certain type of background for its contextual effect. The selection of either future time expression will reduce the processing cost.

At this point the reader might very well object than my proposal is not fundamentally different from the descriptive accounts discussed above: again be going to orients the utterance towards a present context or places it in present perspective, while will is future-oriented. This observation is correct. However, there is a principled distinction between my account and the informal descriptions offered earlier. In my proposal the distinction between the interpretations of will and be going to is not one that is part of the sentence grammar. The contrast is one that comes into play at the level of contextualization of the utterance, since these various expressions of future time contain processing instructions.

Following Smith's account of the distinction between present perfect and 
simple past one could say that truth-conditionally sentences such as (32a) and $(32 \mathrm{~b})$ are equivalent (see Section 5.2 though):

(32) (a) I'll kill him.

(b) I'm going to kill him.

One cannot simultaneously affirm (32a) and deny (32b), for instance. The role of the selection of the distinct future time expressions constructions is to save processing cost by constraining the possible contextualizations of the proposition. In a present tense context such as $(32 \mathrm{c}),(32 \mathrm{a})$ is less appropriate than $(32 \mathrm{~b})$ because the former requires an extension outside the present context and the latter does not:

(32) (c) What are you doing?

Let us turn to scome illustrations of the approach I am advocating here by looking at examples of contextualization.

\subsection{Future time expressions and context}

5.3. I. Ellipsis and will. In $(32 \mathrm{~b})$ be going to signals that the utterance containing it is to be processed in the present, i.e. in the immediately accessible context. In (32a) will signals that the relevant context is future. This does not necessarily mean that there must always be an overt linguistic co-text for processing a proposition. First of all, any utterance has a present context by default: any utterance will be made at some time and in some situation. Confronted with an utterance containing be going to, the hearer will access present propositions whether these be linguistically realized or part of the present background of the utterance. On the other hand, confronted with an utterance with will, the hearer will have to access future propositions. These propositions again need not be realized in the context, but it is less likely that the speaker will be able to have recourse to a default future context. The accessing of a future context is therefore less straightforward and it is not surprising that in isolation an utterance such as ( $15 \mathrm{a})$, repeated here for convenience as (33) is felt to be incomplete:

\section{(33) The rock will fall.}

The incompleteness of (33) is not due to the fact that sentence-internal material is missing. Rather the hearer perceives the utterance as incomplete because he lacks any clues as to the contextualization of the utterance: he needs further guidelines as to where to access the future propositions in which to process the proposition expressed by (33).

In certain circumstances, however, an utterance with will in isolation may not be felt to be incomplete at all. Consider the following example:

(34) You'll wake up the baby. 


\section{BE GOING TO AND WILL}

In a context where someone is moving noisily through the house, (34) does not need a contextual specification of the future context to be accessed: clearly what the speaker intends is: "if you go on making so much noise you will waken her up and then the consequences will be...'. In the context sketched it is clear which future propositions must be accessed and there is nothing deficient about (34).

5.2.2. Conditionals. The observation made above (Section 3.2) that the use of conditionals was restricted very much to will-sentences is not surprising. Assuming that the antecedent of a conditional sentence serves as a context setter (cf. Haiman, 1978 on conditionals as topics and more recently Smith \& Smith, 1988) we may expect that only present time conditions will work well with be going to. A future antecedent would imply a contradiction in the processing instructions, be going to directing the hearer to a present time context and the future antecedent fixing a future context. Hence the oddness of (35a) as opposed to (35b) or (35c):

(35) (a) You're going to be fired if you ever go near his computer.

(b) You'll be fired if you ever go near his computer.

(c) You're going to be fired if you go on like this.

In (35a) the time adverb ever refers to the future, hence the most immediately accessible context which the speaker is putting forward is not the one that the use of be going to would make the hearer turn to. On the basis of be going to the hearer would expect that the context is a present time proposition. In $(35 \mathrm{~b})$, on the other hand, the future time referred to in the conditional subclause (ever) is appropriate because the main clause contains will. $(35 \mathrm{c})$ is also appropriate: the adverbial like this relates to the present time. Thus the context that is given in the subclause is the one expected on the basis of the use of be going to. ${ }^{10}$

5.2.3. Present indication, present cause, present intention. Following the proposal above that be going to constrains the processing of the proposition with which it is associated to the present context, we no longer see the different notions such as present intention, present indication, present cause etc. (see Section 2.I) as specific inherent meanings of be going to. These interpretations follow naturally from the present time contextualization of the construction: a future event may be linked up to the present context in many ways of which present intention, cause and indications are possibly the

[10] An anonymous referee of the paper points out that the examples such as ( 32 a) are "less odd than they were'. He suggests that this may indicate that 'as ever, sophisticated distinctions tend to be lost as "new" form is over-used'. This is an interesting suggestion which would obviously have to be looked into in more detail. The study of the diachronic development of tense selection might throw light on this issue. I have nothing to contribute to this interesting point here. 
most typical. The following examples illustrate this type of contextualization. Note that there is a degree of indeterminacy about which specific association is predominant: the examples in (36) contain notions of intentionality on the part of the subject and also notions of present indications as perceived by the speaker.

(36) (a) You seem to have brought an awful lot of stuff with you. What are you going to do? Play golf? Hunt or something? (Survey of English Usage, Written material, W.5.ra.19)

(b) - Here, give me that.

Looking away, Madeleine said sharply:

- What are you going to do?

(Survey of English Usage: Written material: 6.1.28.2) ${ }^{11}$

The same line of argument allows us to capture the claim often made that be going to is a more immediate future than will. It is more immediate not by inherent meaning but because one only has to access present propositions, or more accurately propositions that one at present has reason to believe are true. $^{12}$

5.2.4. Further cooccurrences. It has been pointed out (Section 2.I.2) that be going to is preferred in combination with already. As mentioned above, already is an adverb of time which also has a discourse function in that it not only indicates the time to be associated with the proposition but also the context in which it needs to be processed, namely the present time or the context of the utterance. Predictably, then, this adverb is to be found with the present perfect and with be going to. Other contextual elements favouring be going to are constructions such as I didn't realize that, did you know that, which also serve to link the subordinate clause they introduce to the present situation:

(37) (a) I didn't realize that you $\left\{\begin{array}{l}\text { are going to } \\ \text { ? will }\end{array}\right\}$ travel by boat.

(b) Did you know that Ann $\left\{\begin{array}{l}\text { is going } \\ \text { ? will }\end{array}\right\}$ to get married?

5.2.5. Equivalence. If we accept that will and be going to are truthconditionally equivalent, then it is not surprising that in certain sentences they are near-interchangeable, as argued by Palmer (see Section 2.I.I). It is when the sentences are contextualized that one construction will often be

[II] I would like to thank Professors R. Quirk and S. Greenbaum for allowing me to use the material of the Survey of English Usage.

[12] I wish to thank Nigel Vincent for pointing this consequence out to me and for his very helpful remarks on the phenomenon. It is interesting that the French equivalent of be going to, the future with aller ('go') is referred to as the 'futur proche'. 
preferred over the other. Speakers may also vacillate between the two constructions as they shift their perspective, the contextualization of the utterance, from present to future and back. In some cases, it may indeed be fairly immaterial in which context exactly the proposition is processed. This would be so in those cases where in both a present and a future context there are sufficient inferences to be derived to make the proposition relevant. Consider for instance:

(38) (a) Now we'll have no bread left for tomorrow's breakfast.

(b) Now we're going to have no bread left for tomorrow's breakfast.

( 38 a) directs the hearer towards the future implications of the proposition (i.e. tomorrow's breakfast) and ( $38 \mathrm{~b}$ ) directs him to the present implications (i.e. what to do about the situation now). (See discussion in Section 2.2 of the use of now in such examples.)

Given that the choice between will and be going to is not a 'grammatical' choice, but rather one of giving processing instructions, there is inevitably a subjective element in the selection of the future referring construction. Hence the importance attached to the point of view of the speaker in the descriptive studies discussed in Section 2.I. It will not be possible, indeed it would be undesirable, to provide a hard and fast rule to determine each individual occurrence of be going to or will. It is also to be expected that an inappropriate use of one of the constructions by non-native speakers does not lead to ungrammaticality. The 'oddness' of (35a) above for instance results from contradictory processing instructions. As argued before, however, this does not mean that we ought to consider these examples as simply unidiomatic. As pointed out before, the idea of idiomaticity suggests that we are dealing with an accidental property of the language, while I have tried to show that the selection of be going to is entirely systematic. One can arrive at a systematic description of the use of sentences with will or be going to only in a framework that permits individual sentences to be related to sets of background propositions, that is to say to a context.

5.2.6. Contextual inferences. The account given above also allows one to deal with the contextual inferences associated with the use of will and be going to in the following examples:

(39) (a) He won't finish his Ph.D. and he'll lose his job.

(b) He's not going to finish his Ph.D. and he's going to lose his job.

(39a) suggests strongly that the fact that he does not get his Ph.D. is the cause of him losing his job; this implication is far less obvious in ( $39 \mathrm{~b}) .(39 \mathrm{~b})$ may also be a mere list of negative expectations and speculations. It seems 
inappropriate to try to link the causal implication of (39a) with the use of will since a similar contrast to that in (39) is found in (40):

(40) (a) He didn't finish his Ph.D. and he lost his job.

(b) He hasn't finished his Ph.D. and he has lost his job.

(40a) strongly suggests that the one event causes the other, $(40 \mathrm{~b})$ could be taken as a mere list. ${ }^{13}$

Before we look into the explanation for the contrast we need to consider the role of and in utterance processing. I shall not discuss the literature here but I shall adopt the proposals put forward in recent work by Blakemore (1985, 1987). Blakemore argues that the function of the coordinator and is to indicate that

there is a conjoined proposition that has relevance over and above the relevance of its conjuncts taken individually (1985:7)

The hearer himself has to establish in what way the conjoined proposition has this extra relevance. One way in which the conjoined proposition gains relevance is in that it offers a list:

there are all sorts of reasons for producing a list. But whatever it may be it is clear that the relevance of the utterance hinges on the fact that each conjunct is part of a list (i.e. interpreted against the same set of contextual assumptions) rather than on its own individual contextual implications (1985:5)

In other cases of coordination the relevance of the conjoined proposition will be that there is a sequential relation between the first and the second conjunct:

(4I) (a) The king raised his glass and drank.

The second conjunct in (4I a) is interpreted as following the first. To obtain this sequential reading the hearer has to supply propositional elements not present in the linguistic material. In yet other cases the link between the two conjuncts may be causal:

(4I) (b) The road was icy and I slipped.

The relevance of a conjunction of propositions may also be that they are contrastive:

(41) (c) John lives in a flat in town and Mary lives in a cottage in Devon.

Let us now return to (39). In (39a) the causal link is prominent. This is to be expected under Blakemore's account. We have two propositions linked by

[13] One anonymous referee did not seem to agree with this parallelism. Other native speakers I consulted shared my intuitions. Perhaps this is another instance where for some speakers the distinctions between tense forms are being blurred? 
and. The coordinator instructs us to look for a relevance over and above the individual relevance of the propositions. The two events referred to in the propositions are future and moreover the use of will in each of the propositions instructs us to contextualize them in the future. In other words, we can process the propositions against each other, specifically the second conjunct he'll lose his job can be processed against the proposition he won't finish his Ph.D. One background proposition that the hearer may bring to bear on the interpretation of ( $39 \mathrm{a})$ is that 'if you don't finish your Ph.D. you may lose your job'. By using this background assumption the hearer will establish the relevance of the coordination as one of causality: one future event may cause the other.

In (39b) and again tells us to look for some extra relevance for the coordinated proposition. But in both conjuncts be going to directs us towards a present-time context. Both propositions refer to future events, but they must not be processed against the future background of these events. The future event in the first conjunct will thus not normally serve as the background for the contextualization of the second conjunct. The future related background proposition 'if you do not finish your Ph.D. you may lose your job' also is not accessed because it is not co-present in the time domain set up by the choice of be going to rather than will. ${ }^{14}$ Hence the causal link between the two conjuncts is not the obvious inference.

On the other hand, one commonality between the two propositions is their shared present time context. Both propositions should be processed against a present context. The sentence can, for example, be interpreted as a 'list', to use Blakemore's terminology, of future consequences of a present situation. Along the same lines we can explain the oddness of (42)

(42) ?He won't finish his Ph.D. and he's going to lose his job.

(42) again illustrates contradictory processing instructions : the first conjunct tells us to look outside the immediately accessible present context to the future and the second tells us to restrict the focus of contextualization to the present. Assuming Smith's account of the contrast simple past vs present perfect, the different interpretations in (40) follow in the same way as those in (39), but with past replacing future. An account of the contrast will/be going to in terms of processing has a better chance of capturing the similarities between (39) and (40) than one which links the specific reading of (38a) with the 'inherent' properties of will (cf. Wekker, I976: I28).

\section{Problems for further discussion}

My account above relates the differences between future time expressions to linguistically encoded processing constraints. Will-sentences and be going to-

[14] Thanks to Nigel Vincent for helpful discussion of this section. Obviously he cannot be held responsible for the use I have made of his suggestions. 
sentences are said to be truth-functionally equivalent. If truth conditions are determined at the level of sentence meaning, i.e. the semantic level (see Kempson, 1987,1988 , and forthcoming for discussion though), my proposal raises a number of problems with respect to the semantic representation of these future tense forms. At this point I cannot offer any answers to the problems raised and I hope that further research can throw light on them.

\section{I. Tense representation ${ }^{15}$}

In Section $3.2 \mathrm{I}$ briefly introduced the Reichenbach type representation of tense, and discussed the possibility that the contrast between present perfect and simple past and that between will and be going to could be treated in parallel fashion if one is willing to depart from Reichenbach's own analysis of the future time expressions in English and adapt his representation of the contrast between futur proche and futur simple to English:

(43) (a) Simple past

(b) Present perfect

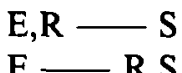

(44) (a) I'm going to see John.

(b) I shall see John
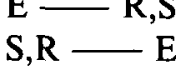

$S-R, E$

The first question that may be asked is what such tense representations are supposed to represent. Hornstein (1977) adopts the Reichenbachian system with some modifications and associates a truth-conditional account to it: different tense representations are linked with different truth-conditions. If each distinct representation encodes different truth conditions, then to assume a different representation for the constructions in (43) and (44) runs counter to the proposal outlined above, in turn based on Haegeman (1981), that these constructions are truth-conditionally equivalent.

Another option is to argue that the representations above (or alternative representations of the same type, see Hornstein, $198 \mathrm{I} ;$.Vikner, 1985, and others) do not encode only the linguistically determined aspects of sentence semantics, which would be relevant at the level of logical form. One might propose that they also encode processing constraints which are not implemented at the sentence internal level but come into play at the level of contextualization of the utterance (cf. also Kempson, I988a,b,c for the interaction of semantics-pragmatics with respect to deixis). On the latter proposal one might argue that it is the element $\mathrm{R}$ (the 'point of reference') that encodes the contextualization constraint. In other words, $\mathrm{R}$ is like a

[15] I wish to thank Sten Vikner for discussing this section with me. He is not to be held responsible for my interpretation of his suggestions. In fact, I suspect he wholeheartedly disagrees with it. 
grammatically encoded pragmatic connective. Reichenbach himself points out that

the determination [of the point of reference $-\mathrm{LH}$ ] is rather given by the context of speech. In a story, for instance, the series of events recounted determines the point of reference (1947: 288)

However, this approach will run into far-reaching problems once we take into account 'complex tenses' such as the future in the past and the past perfect, problems which I discuss in the next two sections. I do not propose a new account of tense interpretation at the level of logical form, but merely list the problems.

\subsection{The future in the past ${ }^{16}$}

The proposal that will and be going to are truth conditionally equivalent faces serious problems when we turn to 'future in the past'. Consider (42):

(45) (a) The Queen would arrive three hours later.

(b) The Queen was going to arrive three hours later.

In the event that the Queen did not arrive, the first sentence appears to be false, but the second is probably true. I have no complete analysis to offer here. One way of solving the problem could perhaps be to say that ( 45 a) entails (45b) (see Kempson, I977: 136, for a similar approach to ambiguity and quantifier scope) and that a speaker wishing to convey (45b) would not be respecting the principle of relevance when uttering (45a). This might mean that the sentence with will ( $45 \mathrm{a})$ is not strictly speaking 'false' but rather increases the processing cost. By using be going to (as in (45b)) rather than will (as ( $45 \mathrm{a})$ ), the speaker would have saved his interlocutor processing time in directing him immediately to the relevant entailment, rather than leaving him to work ( $45 \mathrm{~b}$ ) out on the basis of ( $45 \mathrm{a})$. For a full understanding of what is happening in (45), however, one would need to have a fully developed account of the interaction of the different tense markers in complex tenses.

\subsection{Complex tenses}

The problem raised in Section 6.2 leads to the more comprehensive question of how to treat the complex tenses. The discussion is speculative and I have no conclusive proposal to offer. Consider the examples in (46).

(46) (a) Past perfect: He had worked.

(b) Future in the past (i): He was going to work.

(c) Future in the past (ii): He would work.

[16] This problem was pointed out to me by an anonymous referee of $J L$. I thank him or her for bringing the problem to my attention and for suggesting a possible approach. Needless to add, he or she is not to be held responsible for the use I have made of the suggestions. 
6.3.I. The past perfect. In ( $46 \mathrm{a})$, perfective auxiliary have is used in the past tense. In this example have does not constrain the hearer to look for present time propositions in which he has to process the utterance. Reichenbach assigns the representation (47) to (46a):

$$
\text { (47) } \mathrm{E}-\mathrm{R}-\mathrm{S}
$$

If we were to posit that $R$ encodes constraints on contextualization, then we would conclude that $(46 \mathrm{a})$ will be processed against propositions located at a point in time prior to the moment of speech but subsequent to the Event time. This seems intuitively to be correct. However, if $\mathbf{R}$ encodes processing constraints and were to play no role in determining truth conditions, this would also imply that the past perfect as represented in (47) is truth conditionally equivalent to the simple past and the present perfect, since in all three representations $E$ precedes $S$ and $R$ is taken to be irrelevant for truth functions, contrary to fact. ( 48 a) with a simple past is not truth conditionally equivalent to $(48 \mathrm{~b})$ with a past perfect in the main clause:

(48) (a) Mary left when John arrived.

(b) Mary had left when John arrived.

It thus seems that $\mathrm{R}$ cannot solely be seen as a contextualization element unless one were to envisage far reaching modifications of Reichenbach's system. One possibility would be to modify Reichenbach's system, perhaps by introducing further time points. I leave this for further research (see Vikner, 1985, for an alternative system to Reichenbach).

Alternatively (following Kempson, I $988 \mathrm{a}$, b), one might develop a more radical alternative in which the logical form of the sentence, that is the tense representations, does not suffice to determine the truth conditions of the propositions. Roughly, the idea would be that the logical form imposes constraints on the truth conditions and that the contextualization then will fully determine the truth conditions. In such a view, truth conditions would be a function of both the semantics of tense and of its role in contextualization and processing. Relevance theory comes into play at the latter level. At this point I cannot provide a definitive solution for this problem. I hope that further research into the relative role of semantics and pragmatics in determining truth conditions may throw light on this complex issue.

6.3.2. The future in the past. The representations for 'future in the past' in (46b) and (46c) - which correspond to the problematic (45a) and (45b) discussed in 6.2 -raise further problems. Reichenbach proposes three representations for the 'posterior past' illustrated in (49d):

(49) (a) $\mathrm{R}-\mathrm{E}-\mathrm{S}$

(b) $\mathrm{R}-\mathrm{S}, \mathrm{E}$ 
(c) $\mathrm{R}-\mathrm{S}-\mathrm{E}$

(d) She told me that the letter would be sent by internal mail.

The three distinct representations are motivated by the fact that in a sentence like (49d) the arrival of the letters may be prior to, simultaneous with, or subsequent to the moment of speech (see Vikner, I985, for discussion).

It is not clear to me how Reichenbach's system of tense representations could distinguish the 'posterior future' with will in ( $46 \mathrm{c})$ from that with be going to in (46b). Reichenbach himself does not discuss be going to as used in ( $46 \mathrm{~b})$, through the construction is said to be that used for the posterior future.

(50) (a) He will be going to work (1947: 297).

(b) $\mathrm{S}-\mathrm{R}-\mathrm{E}$.

One possible approach is to depart from Reichenbach's system and to treat all the constructions with be going to outside the tense system properly speaking and to treat it perhaps as some aspectual marker. In an eight tense system such as that developed by Vikner (1985), for instance, the forms with be going to are excluded from the tense system, as is the futur proche in French. One argument in favour of this proposal is that be going to is found with all tense forms. To give some examples:

(51) (a) Present tense

He leaves.

$\mathrm{He}$ is going to leave.

(b) Past tense

He left.

He was going to leave.

(c) Future tense

He will leave.

He will be going to leave.

(d) Present perfect

He has left.

He has been going to leave.

(e) Past perfect

He had left.

He had been going to leave.

etc.

Whichever approach one adopts for the tense representations, however, the specific pragmatic function of be going to outlined above can be maintained. The construction would encode an instruction to contextualize a proposition which refers to a future state of affairs at the time determined by the grammatical tense. For instance, in ( $5 \mathrm{I}$ a) there is an instruction to process a future proposition in the present, in $(52 \mathrm{~b})$ in the past. If simple past and 


\section{LILIANE HAEGEMAN}

present perfect are taken to be part of the tense system (as is the case in Reichenbach, 1947, and in Vikner, 1985) this would, however, entail that the contrast between be going to and will is treated in a way which differs from Smith's (I98I) treatment of present perfect and simple past, which was the starting point for our discussion.

At this point I cannot solve the problems raised above. Much depends on the overall approach to tense and aspectual auxiliaries and to the relation of tense representations and truth conditions.

\section{Author's address: Départment de langue et littérature anglaises, Université de Genève, $22 \mathrm{Bd}$ des Philosophes, CH-I205 Genève, Switzerland.}

\section{REFERENCES}

Binnick, R. I. (1972). Will and be going to. Papers from the Seventh Regional Meeting Chicago Linguistics Society. 40-52.

Blakemore, D. (1985). Discourse connectives and conjoined utterances. Paper presented at the LAGB meeting, Liverpool, 1985 .

Blakemore, D. (1987). Semantic constraints on Relevance. Blackwell.

Blakemore, D. (1988). So as a constraint on relevance. In Kempson, R. (1988c). 183-195.

Close, R. (1977). Some observations on the meaning and function of verb phrases having future reference. In Bald, W-D. \& Ilson, R. (eds) Studies in English usage: the resources of a presentday English corpus for linguistic analysis. Frankfurt: Peter Lang; Bern: Herbert Lang. 125-156.

Ehrlich, S. (1987). Aspect and point of view. Paper presented at the International Pragmatics Conference, Antwerp, August 1987.

Enç, M. (1987). Anchoring conditions for tense. $L$ In $18.633-657$.

Fleischman, S. (1982). The future in thought and language. Cambridge: Cambridge University Press.

Grice, P. (1975). Logic and conversation. In Cole, P. \& Morgan, J. (eds) Syntax and Semantics 3. New York: Academic Press. 4I-58.

Haegeman, L. (1981). The use of will and the expression of future time in present-day British English. Unpublished Ph.D. diss. University of Ghent.

Haegeman, L. (1983a). Be going to, gaan and aller: some observations on the expression of future time. IRAL, Vol. xxi, 2. $155^{-1} 57$.

Haegeman, L. (1983 b). The semantics of will in present day British English. Verhandelingen van de koninklijke Academie voor Wetenschappen, Letteren en Schone Kunsten van België, klasse letteren. 45.103. Published by John Benjamins.

Haiman, J. (1978). Conditionals are topics. $L g$ 54. 564-589.

Hopper, P. (1979). Aspect and foregrounding in discourse. In Givon, T. (ed.) Discourse and syntax. (Syntax and Semantics 12.) Academic Press: New York. 213-24I.

Hopper, P. (1982). Aspect between discourse and grammar: an introductory essay for the volume. In Hopper, P. (ed.) Tense-aspect: between semantics and pragmatics. Amsterdam/Philadelphia : John Benjamins.

Hornstein, N. (1977). Towards a theory of tense. $\operatorname{LIn} 8$. 521-557.

Kempson, R. (1977). Semantic theory. Cambridge: Cambridge University Press.

Kempson, R. (1988a). The relation between language, mind, and reality. In Kempson, $R$. (I988c). 3-25.

Kempson, R. (1988b). Logical form: the grammar cognition interface. $J L 24.393-43 I$.

Kempson, $\mathrm{R}$. (ed.) (1988c). Mental representation: the interface between language and reality. Cambridge: Cambridge University Press.

Leech, G. N. (1971). Meaning and the English verb. Longmans: London. [Second edition: 1987.]

Palmer, F. R. (1974). The English verb. Longman: London. 
Palmer, F. R. (1979). Modality and the English modals. Longman: London.

Quirk, R. et al. (1985). A grammar of English. Longman: London.

Reichenbach, H. (1947). Elements of symbolic logic. New York: The Free Press.

Smith, N. V. (198I). Grammaticality, time and tense. Paper presented to the Royal Society/Britich Academy discussion meeting on The Psychological Mechanisms of Language. Published in Phil. Trans. R. Soc. London. B. 259. 253-265.

Smith, A. \& N. V. (1988). A Relevance-theoretic account of conditionals. In Language, speech and mind: studies in honour of Victoria A. Fromkin. Hyman, L. \& Li, C. N. (eds). London \& New York: Routledge. 322-352.

Sperber, D. \& Wilson, D. (1986). Relevance. Oxford: Blackwells.

Vet, C. (1984). Is there any hope for the 'futur'? In Bennis, H. \& van Lessen-Kloeke, W. U. S. Linguistics in the Netherlands, 17. 189-196.

Vikner, S. (1985). Reichenbach revisited: One, two or three temporal relations? Acta Linguistica Hafniensia 19 18-35.

Wekker, H. C. (1976). The expression of future time in contemporary British English. Amsterdam: North Holland. 